\title{
AVALIAÇÃO DE HERBICIDAS APLICADOS EM PRÉ E PÓS-EMER GÊNCIA NA CULTURA DA CEBOLA (Allium cepa L,)
}

\section{J.C. FERREIRA}

Eng $^{0}$ Agr $^{\circ}$, M.Sc., Herbicidas e Plantas Daninhas, EMBR APA-

Centro de Pesquisa Agropecuário do Trópico Semi-Árido (CPATS A), Caixa Postal 23, 56300 - Petrolina, PE

\section{RESU MO}

Foram conduzidos em áreas de agricultores do Projeto de Irrigação de Bebedouro, no município de Petrolina, PE, dois experimentos de campo, onde estudouse o comportamento de diferentes herbicidas, no controle de plantas daninhas e na tolerância da cultura da cebola transplantada. Os tratamentos foram distribuídos em blocos ao acaso com três repetições, em um Latossolo Amarelo, fase arenosa, com baixos teores de argila $\mathrm{e}$ matéria orgânica.

No experimento I aplicaram- se oxadiazon 1,00, pentimethalin $1,25 \mathrm{e}$ napropamide $1,50 \mathrm{~kg} / \mathrm{ha}$ em pré-emergên cia, dois dias após o transplante; oxifluorfen 0,24 e $0,48 \mathrm{~kg} / \mathrm{ha}$ em pós-emergência precoce, dez dias após o transplante; oxadiazon 1,00, oxadiazon $1,00+$ sulfato de amônio 5,00, bentazon 0,72 , acifluorfen sódico 0,32 , dinoseb acetato 1,50, sethodydim 0,23 , alloxydim-sodium 1,12 , diclofop -metil 0,72 e bentazon $0,72+$ sethoxy $\operatorname{dim} 0,23 \mathrm{~kg} / \mathrm{ha}$ em pós -emergência, 14 dias após o transplante. No ex- perimento II aplicaram-se oxadi azon 1,00, oxifluorf en 0,48 e 0,96 napropamide 1,50 e $3,00 \mathrm{~kg} / \mathrm{ha}$, aos dois dias após o transplante; oxifluorfen 0,48 e 0,96 , bentazon 0,72 e 1,44, acifluorfen sódico 0,27 e 0,54 , dinoseb acetato $1,503,00$ e bentazon $0,72+$ sethoxy dim $0,23 \mathrm{~kg} / \mathrm{ha}$, aos 14 dias após o trans plante.

Em avaliações realizadas aos 20 e 34 dias após o transplante da cultura, respectivamente nos experimentos I e II, constataramse al tos índices de controle da comunidade daninha pelos herbicidas oxadiazon e oxifluorfen. Entre os outros tratamentos, destacaram-se o acifluorfen sódico no controle de folhas largas e sethoxydim, alloxydim, napropamide, pendimethalin e a mistura bentazon + sethoxyadim no controle de gramíneas.No experimento II, dinoseb acetato e principalmente napropamide afetaram o desenvol vimento da cultura e comprometeram a produtividade.

PALAVRAS -CHA VE: cebola, herbicida, planta daninha, controle químico. 


\section{SUMMARY}

HERBICIDES APPLIED IN PRE AND POSEMERGENCEONTRANSHLANTEDONION

CROP (Allium cepa L.)

Two field experiments were carried out in grower's fields of the Bebedouro Irrigation Project, in Petrolina, PE, in order to study the performance of several herbicides in controlling weeds on transplanted onion crop and the crop tolerance. The treatments were arranged in a randomized complete block design with 3 replications, in a sandy red-yellow Latosol, of low clay and organic matter values.

In the experiment I, oxadiazon (1.00 $\mathrm{kg} / \mathrm{ha})$, pentimethalin $(1.25 \mathrm{~kg} / \mathrm{ha})$ and napropamide $(1.50 \mathrm{~kg} / \mathrm{ha})$ were applied in pre-emergence, two days after transplanting; oxyfluorfen $(0.24$ and 0.48 $\mathrm{kg} / \mathrm{ha}$ ) in early postemergence, ten days after transplanting; oxadiaz on $(1.00 \mathrm{~kg} / \mathrm{ha})$, oxadiazon $(1.00 \mathrm{~kg} / \mathrm{ha})+$ ammonium sulphate $(5.00 \mathrm{~kg} / \mathrm{ha})$, bentazon $(0,72$ $\mathrm{kg} / \mathrm{ha})$, acifluorfen-so dium $(0.32 \mathrm{~kg} / \mathrm{ha})$, dinoseb acetate $(1.50 \mathrm{~kg} / \mathrm{ha})$, setoxy dim $(0.23 \mathrm{~kg} / \mathrm{ha}), \quad$ alloxyd im-sodi um $(1.12 \mathrm{~kg} / \mathrm{ha})$, diclofop-methyl $(0.72 \mathrm{~kg} / \mathrm{ha})$, and bentazon $(0.72 \mathrm{~kg} / \mathrm{ha})+$ sethoxydim $(0.23 \mathrm{~kg} / \mathrm{ha}), 14$ days after trans planting. In the experiment II, oxadiazon $(1.00$ $\mathrm{kg} / \mathrm{ha})$, oxyfluorfen (0.48 and $0.96 \mathrm{~kg} / \mathrm{ha})$, and napropamide (1.50 and $3,00 \mathrm{~kg} / \mathrm{ha}$ ) were applied two days after transplanting; oxyfluorfen $(0.48$ and $0.96 \mathrm{~kg} / \mathrm{ha})$, bentazon (0.72 and $1.44 \mathrm{~kg} / \mathrm{ha})$, aciflu orfen-sodium (0.27 and $0.54 \mathrm{~kg} / \mathrm{ha})$, dinose b ace tate $(1.50$ and $3.00 \mathrm{~kg} / \mathrm{ha})$, and bentazon $(0.72 \mathrm{~kg} / \mathrm{ha})+$ sethoxydim $(0.23$ $\mathrm{kg} / \mathrm{ha}$ ), 14 days after transplanting.

In evaluations made 20 and 34 days after transplanting, respect $i$ - vely in the experiment I and II, high levels of weed control by oxadiazon and oxyflurfen herbicides were observed. Among other treat ments, acifluorfen-sodium was outs tanding in controlling broad leave weeds and sethoxydin, alloxy -dim-sodium, napropamide, pendime thalin and bentazon + sethoxydim mixture in grass control. In experiment II, dinoseb and mainly napropamide affected the develop ment of the onion crop and caused yield reductions.

KEYWORDS: onion, herbicide, weeds, chemical control.

\section{INTRO DUÇÃO}

A cebola, uma das hortaliças de mai or importância para o Brasil, tem sido uma das principais culturas para a região do Sub médio São Franci sco.

A cultura da cebola 6 extremamente sensível à competição exercida pelas plantas daninhas. Suas folhas aciculares e eretas, associadas ao crescimento lento das plantas, interceptam pouca luz e permitem livre germinação e desenvolvimento de plantas daninhas durante quase todo o seu ciclo. Assim, o controle de plantas daninhas constitui-se num dos principais fatores para $o$ aumento de produtividade da cultura de cebola. Segundo Wicks et al. (17), em cultura de semeadura direta, a produção foi reduzida em 20, 30 e $70 \%$ quando as plantas daninhas cresceram livremente por 2,4 e 8 semanas. Em cultura de transplante, a produção foi diminuída em $42 \%$,quando nen hum con trole foi feito até as duas primeiras semanas (10).

A utilização de méto dos mecânicos para controle de plantas daninhas na cultura de cebola 6 dificultada pelo pequeno es paçamento 
entre fileiras. Além disso, o uso de enxada em cultura com mais de sete semanas causa feitos negativos na produção (10), o que torn a o uso de herbicidas uma prática agrícola bastante vantajosa.

O herbicida oxadiazon tem-se apresentado seletivo à cultura da cebola transplantada em diferentes condições de solo e clima $(5,8,12,13,14)$ que, associado à sua eficiência de controle, é, quase sempre, considerado como herbicida padrão. Outros herbicidas têm-se mostrado seletivos à cebola, como pendimethalin (2, $3,15)$, oxifl uorfen $(1,3,14)$ e bentazon(7).

O prese nte trabalho teve como objetivo avaliar o comportamento de diferentes herbicidas aplicados em pré e pósemergência na cultura da cebola transplantada, na região do Vale do Submédio São Francisco.

\section{MATE RIAL E MÉTODOS}

Este trabalho foi realizado a través de dois experimentos durante o ano de 1983, em áreas de agricultores do Projeto de Irrigação de Bebedouro, localizado no municí- pio de Petrolina, PE, em Latossolo Vermelho Amarelo, fase arenosa, cujas características físicas e químicas encontram-se no Quadro 1.

$\mathrm{O}$ delineamento estatístico adotado foi o de blocos ao acaso, com 16 tratamentos e três repe tições.

Os tratamentos químicos foram representados pelos herbicidas oxadiazon, pendimethalin, napropami de, oxifluorfen, bentazon, acifluorfen sódico, dinoseb acetato, sethoxydim, alloxydin-sódium e diclo fop-metil, que aplicados isolados ou em misturas, tiveram sua eficiência e sele tividade avali adas. Const aram ainda dos experimentos 2 tratamentos teste munhas, um com capina e outro sem capina, sendo que no experimento I a testemunha sem capina foi mantida no limpo a partir de 30 dias após o transplante. As respectivas doses e épocas de aplicação encontram-se nos Quadros 2 e 3.

Para aplicação dos herbicidas utilizou se um pulverizador costal, manual, sem pres são determinada, munido de um bico de jato em leque 110.02 , com volu me de calda de 360 a 430 1/ha para as diferentes datas de aplicação.

Quadro 1. Resultados das análises físicas e químicas de amostras do solo (profundidade de 0-20 cm), dos locais onde foram realiza dos os experimentos. Petrolina, 1983.

\begin{tabular}{|c|c|c|c|c|c|c|c|c|}
\hline & \multicolumn{4}{|c|}{ Características físicas } & \multirow{3}{*}{$\begin{array}{c}\text { Classe } \\
\text { Textu- } \\
\text { ral }\end{array}$} & \multirow{2}{*}{\multicolumn{3}{|c|}{$\begin{array}{c}\text { Características } \\
\text { químicas }\end{array}$}} \\
\hline & \multicolumn{4}{|c|}{ Granulometria (\%) } & & & & \\
\hline & $\begin{array}{l}\text { Areia } \\
\text { grossa }\end{array}$ & $\begin{array}{l}\text { Areia } \\
\text { fina }\end{array}$ & Limo & $\begin{array}{l}\text { Argi- } \\
1 a\end{array}$ & & $\begin{array}{c}\mathrm{pH} \\
\left(\mathrm{H}_{2} \mathrm{O}\right)\end{array}$ & $\begin{array}{c}\text { M. } 0 . \\
\%\end{array}$ & $\begin{array}{c}\mathrm{Al}^{+++} \\
\mathrm{eq} \cdot \mathrm{mg} / 100\end{array}$ \\
\hline Experimento I & 30 & 57 & 8 & 5 & areia & 6,0 & 1,47 & 0,05 \\
\hline Experimento II & 18 & 74 & 3 & 5 & areia & 5,3 & 0,55 & 0,05 \\
\hline
\end{tabular}


As parcelas foram constituídas por dois sulcos espaçados de $0,6 \mathrm{~m}$ por $11,0 \mathrm{~m}$ de comprimento no experimento I e, por quatro sulcos espaçados de $0,6 \mathrm{~m}$ por $5,0 \mathrm{~m}$ decomprimento no experimento II.

Os transplantes das mudas de cebola, cultivas Texas Grano 502, foram realizados nos estádios de duas a três folhas, aos 31 e 28 dias após a emergência, correspondentes aos experimentos I e II respectivamente.

Para avaliação do efeito dos herbicidas no controle de plantas daninhas foi feita uma avaliação visual em porcenta gem de controle comparada com as parcelas testemunhas sem capinas, aos vinte dias após o transplante, no experimento I. A partir de 30 dias do transplante todas as parcelas foram mantidas no limpo, utilizan do a capina manual. No experimento II, aos 34 dias após o transplante das mudas, fez-se coleta e contagem das plantas daninhas encontradasem $10 \%$ de área útil das parcelas. Esses dados foram transformados em porcentagem de controle. Determinou-se, também, o peso de matéria seca dessas plantas, agrupadas em monocotiledôneas e em dicotiledôneas. Após esse período, as parcelas foram mantidas no limpo a través da capina manual.

As principais plantas daninhas que apareceram nas unidades experimentais, de ambos os experimentos, foram o caruru-demancha (Ama ranthus viridis ídiA L.) e o capim - alpiste (Eragrostis sp.), com populações não inferiores a 80 e $85 \%$, respectivamente, ao grupo das dicoti-ledôneas e das monocotiledôneas. Em menor número apareceram pimenta d'água (Eclipta alba Hassk), capim-tapete (Mollugo verticillata L.), capim-colchão (Digitaria sp), capim-carrapicho (Cenchrus echina- tus L.), e capim-mão-de-sapo (Dac tyloctenium aegyptium (L.) Beauv.) . Na área do experimento II apareceram, ainda, as latifoliadas perpétua-roxa (Centratherum punctatum Cass.) e poaia (Richardia brasiliensis Gomes) .

O estádio de desenvolvimento das plantas daninhas, no momento da aplicação dos herbicidas em pós emergência, era de duas a quatro folhas para as dicotiledôneas e de três a quatro folhas, com início de perfilhamento, para as gramíneas.

\section{RESULTADOS E DISCUSSÃO}

No Quadro 2 encontram-se os valores de percentagem de controle do total de plantas daninhas, em relação à testemunha sem capina, a valiados visualmen te aos vinte dias após o transplante da cultura, e os dados de produção de bulbos do experimento I.

A infestação daninha, representada basicamente por caruru-de-mancha, com $90 \%$ das dicotiledôneas e por capim-alpiste, com $85 \%$ das gramíneas, foi eficientemente controlada por oxadiazon, 1,00 e oxafluorfen $0,48 \mathrm{~kg} / \mathrm{ha}$, aplicados, respectivamente, em pré-mergência e em pós-emer gência precoce, com índice de controle superiores a $98 \%$. Resultados de outros trabalhos $(2,3)$ confirmam os bons resultados destes herbicidas.

Níveis satisfatórios de controle, acima de $81 \%$, foram obtidos com pendimethalin 1,25 , oxifluorfen 0,24 e pela mistura de tanque de oxadiazon $1,00+$ sulfato de amônio 5,00 $\mathrm{kg} / \mathrm{ha}$. A adição de sulfa to de amônio à calda de oxadiazon, elevou o índice de controle de 70 para $81,7 \%$, em aplicação de pós- 
Quadro 2. Estimativa visual de controle de plantas daninhas e produção de cebola no experimento I. Petrolina, PE, 1983.

\begin{tabular}{|c|c|c|c|c|}
\hline Tratamentos & $(\mathrm{kg} / \mathrm{ha})$ & $\begin{array}{l}\text { Aplicação } \\
\text { d.a.t. (1) }\end{array}$ & $\begin{array}{c}\text { Controle } \\
\%\end{array}$ & $\begin{array}{l}\text { Produção } \\
(\mathrm{kg} / \mathrm{ha})(2)\end{array}$ \\
\hline $\begin{array}{l}\text { 01. Oxadiazon } \\
\text { 02. Pendimethalin } \\
\text { 03. Napropamide } \\
\text { 04. Oxifluorfen } \\
\text { 05. Oxifluorfen } \\
\text { 06. Oxadiazon } \\
\text { 07. Oxadiazon + S. Amônio } \\
\text { 08. Bentazon } \\
\text { 09. Dinoseb acetato } \\
\text { 10. Acifluorfen sódico } \\
\text { 11. Sethoxydin } \\
\text { 12. Alloxydim-sodium } \\
\text { 13. Diclofop-metil } \\
\text { 14. Bentazon + Sethoxydim } \\
\text { 15. Test. com capina } \\
\text { 16. Test. sem capina (3) }\end{array}$ & $\begin{array}{c}1,00 \\
1,25 \\
1,50 \\
0,24 \\
0,48 \\
1,00 \\
1,00+5,00 \\
0,72 \\
1,50 \\
0,32 \\
0,23 \\
1,12 \\
0,72 \\
0,72+0,23 \\
- \\
-\end{array}$ & $\begin{array}{r}2 \\
2 \\
2 \\
10 \\
10 \\
14 \\
14 \\
14 \\
14 \\
14 \\
14 \\
14 \\
14 \\
14 \\
- \\
-\end{array}$ & $\begin{array}{l}98,7 \\
87,7 \\
48,3 \\
85,0 \\
98,7 \\
70,0 \\
81,7 \\
23,3 \\
31,7 \\
61,7 \\
48,3 \\
40,0 \\
25,0 \\
63,3 \\
99,3 \\
-\end{array}$ & $\begin{array}{l}20.202 \text { cdef } \\
23.359 \text { abc } \\
22.475 \mathrm{abc} \\
24.747 \mathrm{ab} \\
25.000 \mathrm{a} \\
20.328 \mathrm{bcde} \\
24.621 \mathrm{abc} \\
16.035 \mathrm{fg} \\
17.803 \mathrm{def} \\
21.121 \mathrm{abcde} \\
24.242 \mathrm{abc} \\
20.833 \mathrm{abcde} \\
17.172 \mathrm{ef} \\
21.591 \mathrm{abcd} \\
23.737 \mathrm{abc} \\
12.753 \mathrm{~g}\end{array}$ \\
\hline C.V. (\%) & & & & 11,05 \\
\hline
\end{tabular}

(1) Dias após o transplante

(2) Médias seguidas da mesma letra não diferem estatisticamente entre si pelo teste de Ducan ao nível de $5 \%$ de probabilidade.

(3) As parcelas foram mantidas no limpo a partir de 30 dias do transplante. 
emergência, provavelmente, devido a uma ação sinérgica causada pelo sulfato de amônio. Efeitos sinérgicos causados pela mistura de sul fato de amônio a herbicidas têm sido relatados para dichlorpop, bentazon e benazolin (16).

Apesar de baixos Indices de controle geral para os demais tratamentos, verificouse bom controle do caruru-de-mancha por acifluorfen sódico e do capim-alpiste por pendimethalin, napropamide, se thoxydin, alloxydim-sodium e pela mistura bentazon + sethoxydim. Ben tazon, dinoseb acetato, e diclopop -metil falharam em controlar satis fatoriamente essas duas plantas daninhas. $\mathrm{O}$ baixo controle do capim-alpiste pelo graminicida diclo fop-metil pode ser atribuído, entre outros fatores, ao estádio de desenvolvimento relativamente avançado das plantas e/ou por tratarse de uma espécie pouco suscetível. Resultados de pesquisas têm revelado grande variabilidade entre espécies de gramíneas à ação de diclofopmetil, de acordo com Andersen (1974), citado por Wu e Santelmann (19) e, também ao estádio de desenvolvimento. Para a do sagem utilizada no presente estudo, tem-se obtido ótimos resultados para o capimmarmelada (Brachiaria plantaginea (Linck) Hitch) somente ate o estádio de três a quatro folhas (6), e somente até duas folhas para o capim - colchão (19) .

Sintomas visuais de fitotoxicidade não foram observados, a exceção de uma pequena e temporária injúria em plantas de cebola que receberam bentazon e acifluorfen sódico. Portanto, os valores de produção obtidos para bentazon, dinoseb acetato e diclofop-metil, estatisticamente inferiores a testemunha capinada, deve-se, provavelmen- te, à competição exercida pelas plantas daninhas com a cultura, dado os baixos índices de controle para os respectivos tratamentos (Quad ro 2).

No experimento II verifica-se, atra vés do quadro 3, que oxadiazon e oxifluorfen aplicados em pré-emergência foram altamente eficientes para controlar as plantas daninhas em geral, tanto pelos índices percentuais de controle, como pelos pesos de matéria seca de monocotiledôneas e de dicotiledôneas. Em pós-emergência, oxifluorfen falhou em controlar satisfatoriamen te gramíneas com três a quatro folhas, mas não as folhas largas. Resultados semelhantes a esses foram obtidos por Nortje (9) e Alspaugh et ai. (3), em relação às gramíneas e às folhas largas, respectivamente.

Os demais tratamentos apresentaram baix os Índices decontrolegeral, porém, ao analisar os dados de peso de matéria seca, observa-se que napropamide e a mistu ra bentazon + sethoxydim controlaram as gramíneas e, acifluorfen sódico as folhas largas. Parcelas tratadas com bentazon produziram significativamente menos, seca de dicotiledôneas do que parcelas que receberam bentazon em mistura com sethoxydin. Este fato deve-se, muito provavelmente, à interferência das gramíneas não controladas por bentazon, no desenvolvimento das dicotiledôneas que lhe escaparam ao controle. Por outro lado, o bom controle de latifolia das por acifluorfen sódico $0,27 \mathrm{~kg} 7$ ha e a pouca ou nenhuma injúria causada às gramíneas, permitiu que estas crescessem sem interferência de outras e produzissem significativamente mais matéria seca do que a teste munha sem capina. 
Quadro 3. Porcentagem de controle do total de plantas daninhas, peso da matéria seca de monocotí ledôneas e de dicotiledôneas, fitotoxicidade e produção de cebola no experimento II. Petrolina, PE, 1983.

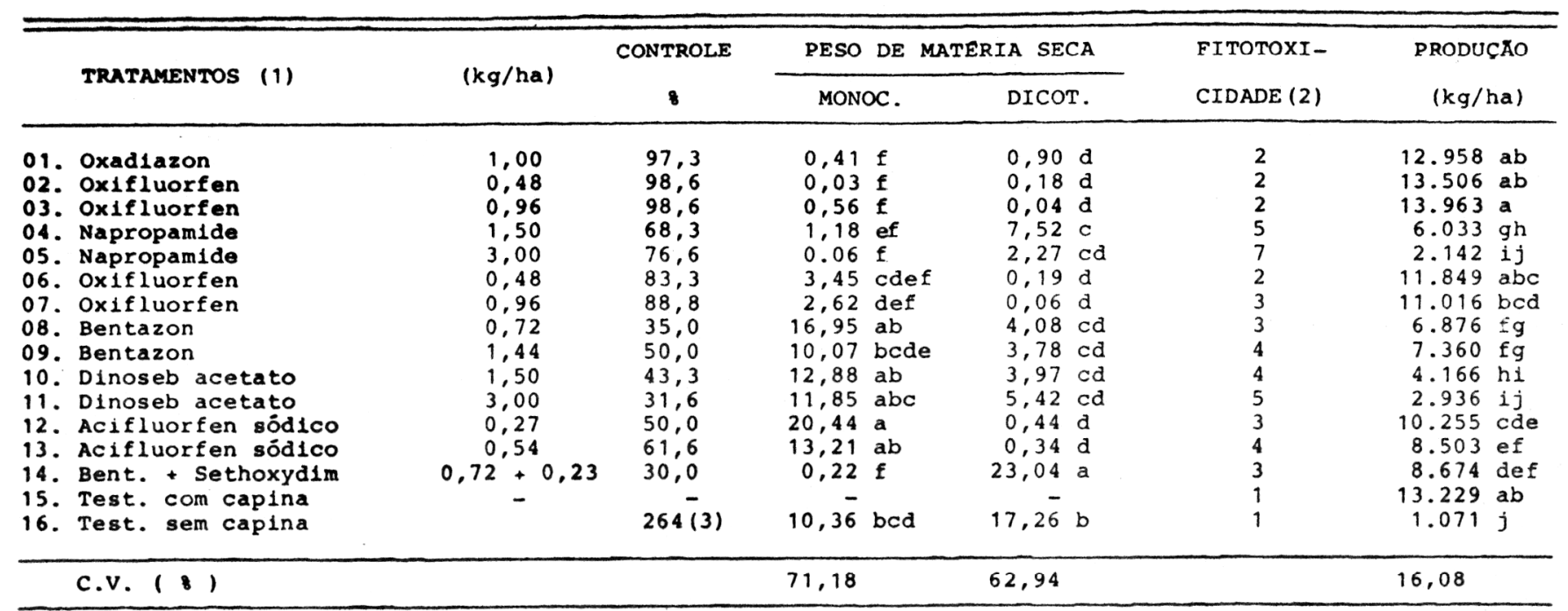

(1) Os tratamentos de 1 a 5 foram aplicados em fré-emergêncla das plantas daninhas, dois dias após o trans plante, es de 6 a 14 em pós-emergêncla, catorze dias após o transplante.

(2) Escala de notas EWRC, onde 1 =nenhum dano e 9 - morte das plantas.

(3) Número mèdio de plantas daninhas $/ \mathrm{m}^{2}$

Obs.: Médias seguidas pela mesma letra não diferem estatisticamente entre si pelo teste de Duncan ao nível de 58 de probabilidade. 
No Quadro 3 encontram-se, também, as notas atribuídas ao grau de fitotoxicidade exibido pela cultura nos diferentes tratamentos, baseadas na escala do Conselho Europeu de Pesquisa sobre Plantas Daninhas (EWRC) e os dados de produtividade.

Plantas tratadas com acifluorfen sódico exibiram folhas levemente retorcidas, mais rígidas e, as vezes, apresentaram estrias longitudinais amareladas. Maior rigidez e retorcimento de folhas foram, também, observadas em plantas que receberam bentazon, não confirmando assim, a plena seletividade observada por Mascarenhas e Lara (7), com aplicação deste produto a 0,48 e $0,96 \mathrm{~kg} / \mathrm{ha}$, sobre plant as com 85 dias ou mais. A ida de avançada dessas plantas pode ter sido decisiva para a maior tolerância a bentazon.

Dino seb acetato e napropamide inibiram o desenvolvimento das plantas e conseqüentemente a produção de bulbos. Plantas que receberam napropamide apresentaram, ainda, uma necrose lenta e gradual dirigindo-se do ápide para a base das folhas, chegando a reduzir $20 \%$ da população de plantas na dosagem de 3,00 $\mathrm{kg} / \mathrm{ha}$. Efeitos adversos na produtividade foram, também, observados por Campbell e Anderson (4), ao aplic arem 4,5 e 6,7 kg/ha de napropamide em cultura de cebola para produção de sementes.

Atribuise a baixa seletividade de dinoseb acetato e napropamide, observada em plantas de cebola no experimento II, ao teor de matéria orgânica muito baixo no solo (Quadro 1), quantidade insuficiente para reter esses herbicidas na superfície de solos arenosos, dada à facilidade com que são lixi viados (18).

Quanto a produtividade observa- se no Quadro 3, que somente tratamentos com oxadi azon e oxifluorfen não diferiram estatisticamente do tratamento testemunha com capina. Os demais tratamentos, sejam pela injúria causada a cebola e/ou pelos baix os índices de controle da comunidade daninha, apresentaram produções signi ficativamente menores em relação a teste munha com capina. A competição das plantas daninhas, durante todo o ciclo da cult ura, redu ziu a produção em $92 \%$.

\section{LITERATURA CITADA}

1. Abada, M.; Zipelevitch,Y.; Gor nik, A. Tests with oxyfluorfen for control of annual weeds in onions. Phytoparasitica, 10(4): 269, 1982.

2. Aita, C.; Guedes, A.C.; Covo1o, L. Competição de herbi cidas no controle de plantas daninhas na cultura de cebola (Allium cepa L.). R.

Centro Ci. Rurais, Santa Ma ria, 12(4): 247-53, 1982 .

3. Alspaugh, K.R.; Abernathy, J. R.; Life, W.N. Efficacy of oxifluorfen in west Texas onion. In: ANNUAL MEETING OF THE SOUTHERN WEED SCIENCE SOCIETY, 35, Atlanta, Ge orgia, U.S.A., 1982. Proceedings. Atlanta, U.S.A. Southern Weed Science Society, 1982. p.136.

4. Campbel1, W.E. \& Anderson, J. L. Effects of no - tillage and herbicides on carrot and onion seed production. HortScience, 15(5): 662-64, 1980.

5. Ferreira, F.A.; Silva, J.F.; Silva, R.F. Controle de er 
vas daninhas na cultura da cebola (Allium cepa L.). R. Ceres, 25(141): $486-90$, 1978.

6. Fleck, N.G. Aplicação do herbicida diclofop na cultura da soja para controle de pa puã, Brachiaria plantagé nea (Link) Hitch. Planta Daninha, 2(1): 5-10, 1979.

7. Mascarenhas, M.H.T. \& Lara, J. F.R. Efeito de doses e épo cas de aplicação do bentazon na produção de duas cul tivares de cebola (Allium cepa L.). Planta Daninha, 3(2): 75-84, 1980.

8. Menges, R.M. \& Tamez, S. Response of onion (Allium cepa) to annual weeds and postemergence herbicides. Weed Sci., 29(1): $74-79$, 1981.

9. Nortjé, P.F. Chemical weed control in onions. Pretoria South Afric Department of Agriculture. Onions, GarIic and Lecks G. 2.

10. Paller, E.C.; Guantes, M.M.; Soriano, J.M.; Vega, M.R.. Duration of weed competition and weed control and yie1d. II. Transplanted onions. The Phyllapp.Agric, 55(5/6): 221-24, 1971 .

11. Randhawa, K.S. \& Bhalla, P.L. The effect of some herbici des on the weed flora and soil microflora in the onion crop (Allium cepal.), and the persistence of their residues in the soil. Indian J. Ecol., 3(1): 3843, 1976.

12. Randhawa, K.S. \& Bhalla, P.L.. The effect of herbicides on weeds of onion in the Pun- jab. PANS, 22(3): 405- 07 , 1976.

13. Silva, J.F.; Silva, R.F.; Ferreira, F.A. Efeito de diferentes herbicidas na cultura da cebola (Allium cepa L.), transplantada na zona da mata-Viçosa-MG. In: EMPRE SA DE PESQUISA AGROPECUARIA DE MINAS GERAIS, Belo Horizonte. Projeto Olericultura, relatório anual 75/76. Belo Horizonte, 1977. p.166-69. 14. Singh, G.; Singh, K.P.; Bandey, U.C. Effect of weedicides on weed control and yield in onion. Pesticides, 16 (10): 9-12, 1982.

15. Sofer, S. \& Gardji,G. Selective weed control in onion. Phy toparasitica, 10(4): 269, 1982.

16. Turner, D.J. \& Loader, M.P.C. Effect of ammonium sulphate and related salts on the phy totoxicity of diclorprop and other herbicides used for broadleaved weed control in cereals. Weed Res., 24(1): 67-77, 1984.

17. Wicks, G.A.; Johnston, D.N.; Nu land, D.S.; Kinbocher, E.J. Competition between annual weeds and sweet spanish onions. Heed Sci., 21(5) :436$39,1973$.

18. Weed Science Society of America, Champaign.

Herbicide Handbook of the Heed Science Society of America. 5 ed. Champain, 1983. p.187-91, p. 337-9.

19. Wu, C-H. \& Santelmann, P. W. Phytotoxicity and soil activity of HOE 23408 . Weed Sci., 24(6): $601-4$, 1976. 